\title{
Nanopartículas y antibióticos: respuesta a la resistencia global bacteriana
}

\author{
Nanoparticles and antibiotics: \\ response to the bacterial global resistance
}

Pág. 34,43

Recibido: 17-07-2020

Aceptado: 11-09-2020

Dr. César Barrantes Murillo ${ }^{1}$

Dr. Gustavo Ortega Oviedo ${ }^{2}$

1,2. Estudiantes de la Facultad de Farmacia, Universidad de Ciencias Médicas, San José, Costa Rica.

\section{RESUMEN}

La resistencia a los antibióticos se ha convertido en una de las mayores problemáticas en tema de salud pública. Su consumo excesivo y venta sin control son las causas principales de la aparición de microorganismos multirresistentes. Por esta razón, la ciencia está innovando en la búsqueda de soluciones que permitan hacer frente a un futuro con antibióticos sin funcionalidad.

Es en este punto donde la nanociencia ha evolucionado a grandes pasos, desarrollando nanopartículas con características fisicoquímicas y farmacocinéticas únicas, con efectos antibacterianos que prometen superar los distintos mecanismos de resistencia y posicionarse como una alternativa viable contra dicha problemática global.

PALABRAS CLAVE:
Antibióticos, multirresistentes, nanociencia, nanopartículas.

\section{ABSTRACT}

Resistance to antibiotics has become one of the biggest problems in public health. The excessive consumption and uncontrolled sale are the main causes of the appearance of multiresistant microorganisms. For this reason, science is innovating in the search for solutions that allow us to face a future with antibiotics without functionality. It is at this point that nanoscience has evolved at great steps, developing nanoparticles with unique physicochemical and pharmacokinetic characteristics, with antibacterial effects that promise to overcome the different resistance mechanisms and position themselves as a viable alternative against this 
global problem.

\section{KEYWORDS:}

Antibiotics, multirresistant, nanoscience, nanoparticles.

\section{INTRODUCCIÓN}

Los antibióticos pueden catalogarse como uno de los avances de la medicina moderna más importantes. Lo anterior es respaldado por los autores Medina \& Pieper quienes enfatizan en su escrito que estos han salvado millones de vidas desde su descubrimiento, no solo por el tratamiento de infecciones bacterianas, sino también por su acción preventiva en aquellos pacientes con mayor susceptibilidad, como por ejemplo los que se asocian a patologías como el cáncer, asma, hipersensibilidad, o bien, involucrados en procesos quirúrgicos importantes como trasplantes.

La población humana se encuentra desde hace algunas décadas en la "era de los antibióticos"; lo cual ha propiciado que se transmita la idea en la población de que este tipo de fármacos son una solución eficaz y perpetua contra las infecciones bacterianas.

Desafortunadamente, aunque la aseveración anteriorrepresentaelescenarioideal, actualmente no es más que un planteamiento utópico. Esto porque los avances, descubrimientos y desarrollo en materia de antibióticos, ha ido de la mano con su resistencia, lo cual potencialmente podría llegar a marcar el fin de la "era de los antibióticos" antes mencionada (Fariña, 2016).

Ángles (2018) afirma que "La resistencia a los antimicrobianos actualmente es una de las mayores amenazas para la salud pública mundial, si no se toma medidas urgentes se llegará a la denominada "era post antibiótica", donde ningún antibiótico tendría efectividad en el tratamiento y las infecciones serían mortales, sumado a esto la facilidad de desplazamiento de las personas, tanto en el ámbito nacional e internacional, agrava el problema debido a la diseminación de gérmenes resistentes" (p.4). Cabe destacar que la comunidad médicocientífica ha alcanzado el consenso de que el momento para plantear respuestas a esta problemática ha llegado.

Aunque, gran parte de las soluciones planteadas se enfoca en racionar el uso de estos fármacos, con el objetivo de evitar el escenario anteriormente señalado, hay otras que focalizan sus esfuerzos en el desarrollo de nuevas estrategias farmacológicas, que presenten una susceptibilidad inferior a la resistencia con respecto a las tecnologías actuales, como es el caso de los nanoantibióticos.

El presente artículo tiene como objetivo profundizar en el fundamento, características principales, tipos, ventajas y desventajas de las nanopartículas con función antibiótica; recopilando los avances científicos más importantes en el área y con ello emitir un criterio acerca del verdadero potencial detrás de esta tecnología innovadora, como herramienta de control sobre la amenaza de los microorganismos multirresistentes.

\section{NANOMATERIALES}

La Comisión Europea (2012) define nanociencia como aquella que se orienta al estudio de los materiales a un nivel atómico, molecular y macromolecular, en donde se obtiene 
propiedades fisicoquímicas y biológicas únicas, especialmente en cuanto al área superficial, reactividad y biocompatibilidad se refiere.

A partir de esta rama de estudio, se han desarrollado y caracterizado estructuras y dispositivos mediante su manipulación, dentro de la escala nanométrica, lo cual se ha denominado nanotecnología, haciendo énfasis al manejo de materiales en la escala de 0-100 nm (Fundación Española para la Ciencia y la Tecnología, 2009).

Disminuyendo el tamaño de partícula a ese nivel, se obtiene características fisicoquímicas y biológicas de alto potencial a nivel biomédico, tomando en cuenta desde un punto de vista clínico, facilidades para atravesar membranas fisiológicas, sistemas de liberación de fármacos, efectos más localizados, entre otras aplicaciones que se mencionarán más adelante.

Por otro lado, se deriva de la definición anterior la mención de materiales, estructuras y sistemas manipulados en la escala nano, a lo cual múltiples autores han denominado nanomateriales o nanosistemas.

Como complemento a lo anterior, la Comisión Europea (2012), se refiere a una categorización de nanomateriales según cuántas dimensiones posea en la escala nanométrica que es importante conocer. Si se tiene que únicamente una dimensión es inferior a los $100 \mathrm{~nm}$, se hace alusión a materiales como recubrimientos o films finos. Por el contrario, si posee 2 dimensiones inferiores a los $100 \mathrm{~nm}$, los exponentes más importantes son los nanotubos. En este artículo, la clasificación de mayor interés es la que contempla las 3 dimensiones cartesianas por debajo de los $100 \mathrm{~nm}$, ya que aquí se encuentra las nanopartículas, las cuales serán abreviadas como NPs.
Barhoum, Chan, Dufresne, Dunquah y Jeevanandam, (2018), proponen una categorización de los nanomateriales sin tomar en cuenta sus dimensiones. Barhoum et al. (2018) establecen 4 tipos de nanosistemas. La primera son los nanomateriales a base de carbono, tales como fullerenes, los nanotubos de carbono y el grafeno. La segunda son los nanomateriales inorgánicos, como lo son las nanopartículas metálicas tales como la plata o el oro, o bien a base de óxidos como el óxido de zinc. La tercera se refiere a nanomateriales orgánicos, como lo son los dendrímeros, las micelas, los liposomas y las nanopartículas poliméricas $\mathrm{y}$, por último, la cuarta se refiere a nanomateriales a base de compuestos, donde se encuentran nanoestructuras muy complejas o mezclas de NPs con sólidos de mayor tamaño.

Para el presente artículo, las nanopartículas metálicas, de óxidos metálicos y poliméricos presentan la mayor importancia debido a su extensa utilización a nivel biomédico.

\section{NANOPARTÍCULAS Y SU APLICACIÓN TERAPÉUTICA}

Visto a nivel terapéutico, al tener un tamaño tan pequeño, algunas propiedades farmacocinéticas y fisiológicas, como el área superficial, la reactividad, la mayor facilidad de penetrar barreras anatómicas, así como su biocompatibilidad, representan características prometedoras de aplicación a nivel clínico, cuyo aprovechamiento y desarrollo según la Comisión Europea (2012), da origen al término nanomedicina, que a su vez es definida por la ESF (European Science Foundation) (2005), como el uso de herramientas con un tamaño nano, que tiene como objetivo la búsqueda de mejoras en la calidad de vida a un nivel sanitario, incluyendo su participación en el diagnóstico, prevención y tratamiento de patologías. 
Es por esto por lo que, a nivel clínico y farmacológico, el uso de nanopartículas representa una estrategia de tratamiento innovadora y de mayor eficacia que otros métodos convencionales. Por ejemplo, Caponetti et al (2019), se refiere al diseño de NPs con fluorescencia por medio de la incorporación de fluoróforos en su interior, dando mejoras en las imágenes de RMN.

Por otro lado, Carolyn, D'Almeida y Bradley (2014), resaltan el uso de NPs en la hipertermia, aprovechando NPs magnéticas y campos magnéticos externos, cuya aplicación es prometedora para el tratamiento de tumores malignos.

Sin embargo, el uso de NPs para sistemas de liberación de fármacos, incluyendo los antibióticos y, como agentes antimicrobianos en sí, son los dos parámetros de mayor relevancia, debido a lo que representa como posible solución a la resistencia bacteriana, a lo cual se le dará énfasis en el presente artículo.

\section{ACTIVIDAD ANTIMICROBIANA DE LAS NPS}

En apartados anteriores, se habló de diversas clasificaciones de NPs, ya sea con base en sus dimensiones o en su estructura química. En este caso, Lakshminarayanan, Ye, Young, Li, y Loh, (2018) establecen una clasificación para las nanopartículas con actividad antimicrobiana, separándolas en dos: metálicas y no metálicas. Dentro de las nanopartículas metálicas, destaca el uso de elementos como plata, oro y cobre para su síntesis, mientras que para las no metálicas las poliméricas y las lipídicas.

\section{NANOPARTÍCULAS METÁLICAS}

Este tipo de nanomaterial es uno de los más utilizados debido a su amplio espectro antimicrobiano. Los principales exponentes dentro de esta categoría son las NPs de oro, plata, así como los óxidos de zinc, magnesio, titanio, aluminio, hierro y cobre. Lakshminarayanan et al (2018) y, Qing, Cheng, Li, Zhang, Tang, Wang, Liu y Yun (2018), concuerdan en que, el mecanismo de acción en cada una de estas se asocia a la afinidad que existe entre las NPs y la superficie bacteriana producto de interacciones electrostáticas, junto a la capacidad que poseen de producir especies reactivas de oxígeno (ROS).

\section{MECANISMO ANTIMICROBIANO DE LAS NPs METÁLICAS}

El efecto antimicrobiano propio de las NPs ya sea de plata, cobre, zinc, titanio, magnesio, entre otros, tienen varias similitudes. La actividad contra la integridad bacteriana inicia con la interacción entre estas y la membrana celular. En todos los casos, la atracción electrostática que se genera entre la carga negativa de la membrana y la carga positiva de los iones metálicos, fomenta la adhesión entre ambos, lo que es catalogado por Shao, Hu y Wang (2017), como un proceso de biosorción.

Shao et al (2017), afirma que, dependiendo del tipo de metal asociado a la NP, así va a ser su afinidad a los diferentes grupos funcionales de las proteínas presentes en la membrana celular de la bacteria. Por ejemplo, los iones $\mathrm{Ag}+\mathrm{y}$ $\mathrm{Zn}+2$, tienen alta afinidad por grupos sulfhídrico, mientras que el $\mathrm{Cu}+2$ interactúa principalmente con grupos amino y carboxilo.

Con respecto al mecanismo antimicrobiano de las nanopartículas de plata, Singh, Garg, Pandit, Mokkapati y Mijakovic (2018), proponen que el proceso de adhesión genera la formación de poros en la membrana, lo que produce una 
salida del contenido intracelular de la bacteria (proteínas, ácidos nucleicos, entre otros) causando un desbalance electrolítico que conlleva al ingreso de los iones plata hacia el citoplasma de la célula.

Una vez dentro de la bacteria, estos iones tienen múltiples mecanismos para generar un estrés oxidativo que afecte la integridad celular.

Qing et al (2018), explican en su escrito la capacidad que tienen estos iones metálicos de aumentar la producción de ROS, al inhibir las deshidrogenasas propias de la cadena respiratoria, lo que también se asocia a un retrocontrol negativo en la expresión de enzimas antioxidantes como glutatión (GSH), superóxido dismutasa y catalasa, los clásicos mecanismos antioxidantes a nivel fisiológico. Como resultado de esto, el estrés oxidativo genera apoptosis, peroxidación lipídica y daño al ADN. Este último se debe principalmente a que los iones plata se intercalan entre la purina y la pirimidina, lo que conlleva al rompimiento de los puentes de hidrógeno entre estas bases $y$, por ende, se inhibe la capacidad celular de división y reproducción, afectando irreversiblemente la información genética.

De manera muy similar, Singh et al (2018), propone que las nanopartículas de óxido de zinc también centralizan su efecto en la producción de ROS, específicamente del anión superóxido y el peróxido de hidrógeno, lo que conlleva a una peroxidación lipídica, salida del contenido intracelular de la bacteria y daño a la membrana celular. En este caso cabe resaltar que este tipo de NPs representa una posible solución a los antibióticos de la categoría carbapenémica, por lo que múltiples estudios se han centrado en este tipo de compuesto.
En cuanto a las nanopartículas de cobre, se repite el mismo mecanismo de producción de especies reactivas de oxígeno, con la particularidad de que los iones de cobre tienen mayor facilidad para desplazarse a través de la membrana celular, por lo que su ingreso a la célula es más sencillo.

Por otro lado, las nanopartículas de magnesio presentan los mismos mecanismos antimicrobianos $y$, se le agrega un efecto característico que resulta en la caída del $\mathrm{pH}$ citoplasmático que genera alteración del potencial de membrana.

Un caso particular se presenta en las nanopartículas de oro, en donde no se genera un efecto bactericida ni bacteriostático como en los sistemas anteriores, sin embargo, debido a su alta biocompatibilidad con las células bacterianas, son ampliamente utilizados como nanovehículos. Esto se refiere a la incorporación de antibióticos como la ampicilina (AMP) en el interior de la AuNP, lo cual ha generado resultados positivos en bacterias resistentes a este antibiótico como la P. Aeruginosa y la E.coli. Esto se asocia a dos posibles mecanismos de acción: el uso combinado de AuNP con AMP que logra superar los niveles de beta-lactamasas producidas por la bacteria y a una inhibición de una bomba transmembrana responsable de la resistencia bacteriana a estos fármacos, esto según lo planteado por Singh et al (2018).

Sin embargo, Shamaila, Zafar, Riaz, Shariff, Nazir y Naseem (2017), describen un mecanismo de actividad antimicrobiana, como resultado de una alteración en el potencial de membrana y distintos procesos metabólicos de la bacteria. Esto asociado a modificaciones a nivel del ribosoma, impidiendo la unión del ARNt, colapsando los mecanismos biológicos. También 
estas AuNPs se unen a diferentes grupos tiol de enzimas como las NADH deshidrogenasas, dañando o alterando la cadena respiratoria y, como resultado se da la liberación de ROS, generando estrés oxidativo que conlleva a la muerte de la célula bacteriana.

Otro estudio relacionado a nanopartículas de oro es el de Palmieri et al (2018), en donde se desarrollaron pequeños péptidos sintéticos bioconjugados a nanopartículas de oro híbridas, las cuales mostraron una eficacia prometedora contra las bacterias Listeria y Salmonella a concentraciones submicromolares; en este caso empleando, un mecanismo de acción muy similar al planteado anteriormente

Comparando los diferentes tipos de NPs, se logra deducir en todos los casos un mecanismo de acción muy similar, en donde la adhesión por atracción electrostática y la formación de radicales libres son la base del proceso.

\section{NANOPARTÍCULAS METÁLICAS MODIFICADAS}

El diseño de nanopartículas no solamente se ha centrado en la síntesis de estas utilizando únicamente un metal, sino que múltiples estudios han diseñado estrategias que ayuden a mejorar aspectos de biocompatibilidad, eficacia y posología. Con base en esto, algunas nanopartículas metálicas han sido modificadas, ya sea realizando un cambio estructural en su superficie o bien, siendo complementadas con una red de polímeros.

Hemeg, H. (2017), asegura que si bien es cierto las NPs metálicas logran su efecto bactericida, su constante uso y cambios a nivel de genética bacteriana, ha generado cierto grado de resistencia frente a estas, especialmente las
AgNPs. Otra razón que favorece el diseño de este tipo de NPs, además de ser una alternativa para la resistencia bacteriana, es el hecho de que las dosis de antibióticos necesarias para ejercer el efecto son menores, lo que reduce los posibles niveles de toxicidad y efectos adversos.

Por otro lado, el hecho de recubrir las nanopartículas con distintos polímeros y formar nanocompuestos, en donde se colocan las NPs en una matriz polimérica, favorece aspectos de biocompatibilidad y estabilidad mayores a las NPs metálicas individuales. Este procedimiento ha demostrado eficacia contra múltiples microorganismos como P. Aeruginosa, S. Aureus, Enterobacter Aerogenes, entre otras.

Palza, Quijada y Delgado (2015), complementan lo anterior asegurando la importancia de incorporar iones cobre o sus partículas en diferentes matrices de polímeros. En este caso, se han hecho estos recubrimientos utilizando múltiples compuestos como polivinilmetilcetona, el polivinilo de cloruro, entre otras, en donde se logra una mejora en el efecto bacteriostático.

Un procedimiento diferente es planteado por Hemeg, H (2017), en el cual se propone un diseño de liberación en donde las NPs tengan un objetivo específico. Es decir, se busca modificar la superficie de las nanopartículas utilizando diferentes ligandos 0 anticuerpos, incluso recubrimientos con células específicas, que permitan que la nanopartícula localice un sitio fisiológico y que únicamente ejerza su efecto en ese lugar. Con esto se reduce efectos adversos y se aumenta la concentración de NPs y, por ende se logra un mayor efecto antibacteriano.

Estos procedimientos se realizan principalmente con polímeros como el quitosano, en donde se ha demostrado que utilizar este en conjunto con NPs de plata y cobre, logra un efecto en bacterias 
como Salmonella sp y $\mathrm{S}$. Aureus. También colocar ligandos selectivos como péptidos con diversos aminoácidos en su estructura, produce un efecto importante en bacterias como Staphylococcus sp y Vibrio Cholereae.

Esto refleja el alcance que tienen estas nanopartículas en cuanto a su uso individual o modificado, ambos con un efecto importante a nivel del tratamiento bacteriano.

\section{NANOPARTÍCULAS ORGÁNICAS}

Existe otros tipos de NPs que son ampliamente estudiadas no por su efecto bactericida, sino por su aplicación como vehículos para el transporte de diferentes fármacos, incluyendo los antibióticos. En este caso, las NPs no metálicas, incluyendo las NPs poliméricas y las lipídicas, representan alternativas de estudio como solución a los mecanismos de resistencia desarrollados por las bacterias, especialmente frente a antibióticos como la vancomicina, meticilina y penicilinas.

Kalhapure, Suleman, Mocktar, Seedant y Govender (2015), definen varios tipos de nanopartículas que actúan como vehículos de antibióticos. Por ejemplo, las nanopartículas sólidas lipídicas representan un sistema de liberación coloidal de amplia utilización. En estas, se coloca un compuesto lipídico que tenga un punto de fusión elevado que actúa como el núcleo de la NP. Su carácter lipofílico permite la incorporación de antibióticos que sean lipofílicas, tales como la tobramicina y la norfloxacina. Para finalizar la estructura de esta NP, se recubre con surfactantes anfifílicos.

También se hace referencia a nanopartículas híbridas lipídicas-poliméricas, en donde se formula un núcleo que tiene como base un polímero y se aprovechan las características biomiméticas de los lípidos, generando mejores sistemas de liberación para el antibiótico. En este caso, la categoría de antibióticos fluoroquinolonas, como ciprofloxacina, levofloxacina y ofloxacina, son colocadas en PLGA y recubiertas con fosfatidilcolina como lípido.

Otro ejemplo es el de Herrera, Artunduaga, Ortíz \& Torres (2017), en donde se emplearon nanopartículas de ácido poliáctico sintetizadas mediante el método de emulsión y evaporación de solvente, las cuales fueron cargadas con ofloxacina. Por otra parte, los autores Kwon et al (2017), emplearon nanopartículas biodegradables de silicio con péptidos antibacterianos para el tratamiento de infecciones pulmonares, específicamente por $\mathrm{P}$. aeruginosa.

De igual forman, existen otras alternativas que sirven como sistemas de liberación, tales como los dendrímeros y las nanofibras.

Esto refleja la importancia de este tipo de nanopartículas, en donde el uso de polímeros y compuestos lipídicos representa una alternativa de mejora en el desarrollo de soluciones, frente a los distintos microorganismos multirresistentes.

\section{TOXICIDAD}

A pesar del progreso significativo realizado en la investigación de nanopartículas, las preocupaciones acerca de su potencial toxicidad aún persisten. Los autores Rajchakit \& Sarojini (2017), señalan que uno de los principales factores que contribuye al papel tóxico de las nanopartículas se relaciona a la capacidad limitada que tiene el cuerpo humano para eliminarlas, lo cual obliga a la comunidad científica a dilucidar el efecto que pueden tener

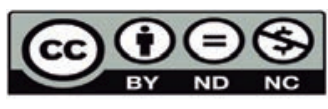


los diferentes materiales empleados en su síntesis.

Debido a su pequeño tamaño, las nanopartículas en general pueden afectar el entorno bioquímico de las células, especialmente si este es menor a $10 \mathrm{~nm}$. Se ha demostrado en estudios tanto en animales como en humanos, que se distribuye a varios órganos (hígado, corazón, bazo, cerebro, pulmones y tracto gastrointestinal) después de su inhalación o ingestión (Marín et al, 2015). A parte del tamaño, existen otros factores que pueden incrementar el potencial tóxico de las nanopartículas como lo son la carga, concentración y composición de estas, cabe destacar que se proyectan a las de origen metálico como las más propensas a causar efectos adversos en el organismo. Lo anterior es respaldado por los autores Beyth et al (2015), quienes afirman que estas han demostrado tener propiedades citotóxicas, genotóxicas y carcinogénicas, lo cual eventualmente podría generar apoptosis, inhibición de proliferación celular, estrés oxidativo, inactivación de enzimas, daño al ADN, desintegración de membranas, entre otros.

Basándonos específicamente en las de origen metálico, las nanopartículas de plata y oro han mostrado los mejores resultados en términos de peligrosidad hasta el punto de que han sido señaladas como no tóxicas para las células humanas; por lo cual se han estudiado de forma abundante en las investigaciones más recientes. En el caso de las de oro se debe a la naturaleza inerte y no tóxica, los autores Rajchakit \& Sarojini (2017), establecen que estas pueden ingresar a la célula a través de la vía de pinocitosis y localizarse en los lisosomas sin entrar en el núcleo, lo que ayuda potencialmente a minimizar su peligrosidad. Además, la naturaleza redox del oro es un beneficio en la reducción del nivel de oxígeno reactivo producido durante la exposición a las nanopartículas.

Por su parte, las de plata han demostrado biocompatibilidad y estabilidad en fibroblastos y queratinocitos, entre otras características, las cuales colocan este material entre las mejores opciones en nanopartículas antibióticas (Herman \& Herman, 2014).

Es evidente que los esfuerzos para dimensionar el impacto y potencial de toxicidad de las nanopartículas antibióticas no puede cesar, ya que resulta fundamental esclarecer el panorama de los efectos negativos que estas podrían ocasionar en el organismo y con ello desarrollar sistemas de liberación más inocuos, sin perder la eficacia por la cual son considerados fármacos de alto potencial clínico.

\section{CONCLUSIONES}

Las nanopartículas han demostrado tener en la última década una cantidad importante de propiedades físicas y químicas que las respaldan para ser utilizadas en un amplio espectro de aplicaciones en el área de la biomedicina y otras ramas afines.

En cuanto a su uso farmacológico, se han perfeccionado diferentes estrategias que dejan en evidencia un potencial innegable, como posible antibacteriano en el tratamiento de algunos de los patógenos con mayor prevalencia a nivel mundial. Aunque, si bien es cierto, se les ha confirmado una toxicidad intrínseca importante, que se debe de erradicar si se plantean utilizar para fines médicos, no cabe duda que son una de las respuestas más viables contra la resistencia bacteriana.

Partiendo de que Organización Mundial a 
la Salud OMS (2017), publica una lista que incluye los patógenos para los que se necesita urgentemente nuevos antibióticos, en la que se engloba 12 familias de bacterias que amenazan diariamente la salud humana, todo apunta a que la comunidad científica va a centrar buena parte de sus esfuerzos en el descubrimiento, desarrollo e innovación de nanopartículas como primera opción contra esta crisis mundial, la cual más allá de ser un peligro se ha vuelto una realidad.

\section{REFERENCIAS}

Ángeles, E. (2018). Uso racional de antimicrobianos y resistencia bacteriana ¿hacia dónde vamos? Revista Médica Herediana, 3-4.

Beyth, N., Houri-Haddad, Y., Domb, A., Khan, W., \& Hazan, R. (2015). Alternative Antimicrobial Approach: Nano-Antimicrobial Materials. Evidence-Based Complementary and Alternative Medicine.

Caponetti, V., Trzcinski, J., Cantelli, A., Tavano, R., Papini, E., Mancin, F., \& Montalti, M. (2019). Self-Assembled Biocompatible Fluorescent Nanoparticles for Bioimaging. Front Chem, 7(168).

European Science Foundation. (2005). European Science Foundation. Obtenido de http://archives.esf.org/ fileadmin/Public_documents/Publications/Nanomedicine.pdf

Fariña, N. (2016). Resistencia bacteriana: un problema de salud pública mundial de difícil solución. Mem. Inst. Investig. Cienc. Salud, 04-05.

Filipponi, L., \& Sutherland, D. (2012). Nanotechnologies: Principles, Applications, Implications and Hands-on Activities. Luxemburgo.

Fundación Española para la Ciencia y la Tecnología. (2009). NANOCIENCIA Y NANOTECNOLOGÍA. Entre la ciencia ficción del presente y la tecnología del futuro. Madrid.

Hemeg, H. (2017). Nanomaterials for alternative antibacterial therapy. Int J Nanomedicine, 8211-8225.

Herman, A., \& Herman, A. (2014). Nanoparticles as antimicrobial agents: their toxicity and mechanisms of action. J Nanosci Nanotechnol, 14(1), 946-957.

Herrera, T., Jhamilton, A., Ortiz, C., \& Torres, R. (2017). Síntesis de nanopartículas de ácido poliláctico cargadas con antibióticos y su actividad antibacteriana contra Escherichia coli 0157:H7 y Staphylococcus aureus resistente a meticilina. Biomédica, 37(1), 11-21.

Jeevanandam, J., Barhoum, A., Chang, Y., Dufresne, A., \& Danquah, M. (2018). Review on nanoparticles and nanostructured materials: history, sources, toxicity and regulations. Beilstein J Nanotechnol., 9(1), 10501074.

Kalhapure, R., Suleman, N., Mocktar, C., Seedat, N., \& Govender, T. (2015). Nanoengineered drug delivery 
systems for enhancing antibiotic therapy. J Pharm Sci, 104(3), 872-905.

Kwon, E., Skalak, M., Bertucci, A., Braun, G., Ricci, F., Ruoslahti, E., . . Bhatia, S. (2017). Porous Silicon Nanoparticle Delivery of Tandem Peptide Anti-Infectives for the Treatment of Pseudomonas aeruginosa Lung Infections. Adv Mater, 29(35).

Lakshminarayanan, R., Ye, E., Young, D., Li, Z., \& Loh, X. (2018). Recent Advances in the Development of Antimicrobial Nanoparticles for Combating Resistant Pathogens. Adv Healthc Mater, 7(13), 1-13.

Marin, S., Vlasceanu, G., Tiplea, R., Bucur, I., Lemnaru, M., Marin, M., \& Grumezescu, A. (2015). Applications and toxicity of silver nanoparticles: a recent review. Curr Top Med Chem, 15(16), 1596-1604.

Medina, E., \& Pieper, D. (2016). Tackling Threats and Future Problems of Multidrug-Resistant Bacteria. Curr Top Microbiol Immunol, 3-33.

Organización Mundial de la Salud. (27 de febrero de 2017). Organización Mundial de la Salud. Obtenido de https://www.who.int/es/news-room/detail/27-02-2017-who-publishes-list-of-bacteria-for-which-new-antibiotics-are-urgently-needed

Palmieri, G., Tatè, R., Gogliettino, M., Balestrieri, M., Rea, I., Terracciano, M., . . . De Stefano, L. (2018). Small Synthetic Peptides Bioconjugated to Hybrid Gold Nanoparticles Destroy Potentially Deadly Bacteria at Submicromolar Concentrations. Bioconjugate Chem, 29(11), 3877-3885.

Palza, H., Quijada, R., \& Delgado, K. (2015). Antimicrobial polymer composites with copper micro- and nanoparticles: Effect of particle size and polymer matrix. Journal of Bioactive and Compatible Polymers, 1(15).

Qing, Y., Cheng, L., Li, R., Liu, G., Zhang, Y., Tang, X., . . Qin, Y. (2018). Potential antibacterial mechanism of silver nanoparticles and the optimization of orthopedic implants by advanced modification technologies. Int J Nanomedicine, 5(13), 3311-3327.

Rajchakit, U., \& Sarojini, V. (2017). Recent Developments in Antimicrobial-Peptide-Conjugated Gold Nanoparticles. Bioconjug Chem, 28(11), 2673-2686.

Roth, B., \& D'Almeida, C. (2013). Medical Applications of Nanoparticles. Journal of Undergraduate Research, 15, 1-10.

Shamaila, S., Zafar, N., Riaz, S., Sharif, R., Nazir, J., \& Naseem, S. (2016). Gold Nanoparticles: An Efficient Antimicrobial Agent against Enteric Bacterial Human Pathogen. Nanomaterials (Basel), 6(4), 71.

Singh, P., Garg, A., Pandit, S., Mokkapati, V., \& Mijakovic, I. (2018). Antimicrobial Effects of Biogenic Nanoparticles. Nanomaterials (Basel), 8(12), 1-19.

Wang, L., Hu, C., \& Shao, L. (2017). The antimicrobial activity of nanoparticles: present situation and prospects for the future. Int J Nanomedicine, 12, 1227-1249. 